\title{
Impulsivity and Self-Sabotaging Behavior: A Case Study
}

\author{
Article by Dion Robeau Thompson \\ Psychology, Texila American University, Bahamas \\ E-mail:dion_thompson@live.com
}

\begin{abstract}
Rush to judgment is a frequently used strategy aimed at helping persons cope with stressors, they deem too demanding on their self-esteem. There are a numerous studies postulated as reasons self-sabotaging from general procrastination, cognitive distortions, to fear of failing, however, studies associated with impulsivity in relation to cognitive processing has been shortcoming. This case study examines the role of impulsivity on cognitive self-sabotaging behaviour. Using the Rosenberg Self-Esteem Scale (Rosenberg, 1965), to identify levels of self-esteem, along with a series of interviews, the findings indicate that there appears to be an association between cognitive impulsiveness and self-sabotaging behaviour. Further studies are needed to assess, to what extent this phenomenon can be applied to a larger population.
\end{abstract}

Keywords: Rush to Judgment, Impulsivity, Low Self-Esteem, Faulty Assumptions, Poor Risk Management, Self-Sabotaging Behavior, Self-Handicapping, Self-Defeating Habits.

\section{Introduction}

Horney (1940) hypothesized that there were ten neurotic needs exercised by persons with limited coping skills. For her, the need for affection and approval was permanent, and governed the remaining strategies used by such persons. She categorized these interactions into three major categories, of which affection, and approval were listed as the main reasons for moving towards others. There was love component missing within their lives and this created a pathology to seek out any and all in order to gain this need. Within the second category, she postulated that a need to move against others was characterized as a need for social recognition and prestige. The result was manifested in a form of protection of unacceptable thoughts, motives and feelings. These feelings were projected onto others as if they were the true source of the discomfort. Finally, the need moving away from others, caused such persons to engage in a restrictive practice to produce an unremarkable style of life. For her, neuroticism was a developed within early childhood due to life experiences, which helped to drive the person towards one of these types of interactions.

Glasser (1998) postulated that these fell with the domain of various needs, for instance, the need for love, came out of a need for support, while power rose out of a need for self-worth and significance. For most persons, the significance was externalized through the need of for power which came in the form of competency.

According to Horney (1940), such persons develop a basic hostility when they were torn between the desires to leave a situation, but was inwardly compelled to remain, due the drive to meet some basic need. The interaction is complicated by the fact that they are dependent upon the person(s) whom they want to be away from. Thus, conflicts resulted in a redirecting the aggrieve desires toward a less threatening target. McCrea and Hirt (2001), reported that there was a global and specific self-esteem at risk when attempts needed to be made, in order to adjust to the circumstances they found themselves within. As a result, they exercised what Tice and Baumeister ((1990) called the self-presentational ploy to address a greater issue: the need to investigate time and energy at the expense of success. Numerous strategies devise to address self-sabotaging behaviors have met difficult practical application (Eronen et al., 1998). The need to protect the self and the esteem as acted as a barrier to the process during any interaction, which cannot always be accounted for during interactions. This form of impulsivity, or emotional reaction to engagement of 
DOI: $10.21522 /$ TIJPY.2016.02.02.Art001

ISSN: $2518-8852$

responsibility has been less studied, and thus needs to be explored more from the level of the individual to gain a sense of what directs it. While these finds might not be applicable to a larger populous because they are narrow in scope, the depth gathered might be of some value, to help shed some light into the background of the process which are at play within the understanding of rushing to judgment and self-sabotaging process.

\section{Method}

The participant is a white European female in her mid-forties who works as an educator in Asia, at a private academic institution for higher learning. She has a doctoral degree, and has taught English for over ten years. She has a medical condition which as caused her to have a physical disfigurement within her joints, which are noticeable, when she move. It was contracted as a teenager. She is a divorced mother of 5 boys, who lives with their father on another continent. She has an estrange relationship with her mother, and very fond of her father. She has a sister to whom she has a rocky relationship.

The participant was unable to establish any close connections or relationship with any of her colleagues. She was unable to accept instructions from her superiors without complaining, expressing strong dislike to be given instructions, the participant requested that all job assignments were negotiated prior to having hem made. The participant often made request which were outside of her contractual agreement, and became very upset when they weren't honored. For example, she wanted to come to work an hour later than was assigned, to accommodate her trip to and from work. Additionally, she requested an extra half an hour lunch time, as the work location was too far from her home or nearby eateries. The participant wanted be consulted on work schedule changes at the administrative level, but was not part of the administrative team.

The interviews of the subject were conducted over Skype as participant had moved to another place of employment at the time of the study. These interviews were conducted during the hours of 9:00 am to 10:00 am, when the participant was at home on vacation during the summer months for a period of 7 sessions. A Rosenberg Self-Esteem Scale (Rosenberg, 1965), self-esteem inventory was completed by the participant after the interviews were completed. The Rosenberg self-esteem is a 10 item scale which measures the global self-worth, both negative and positive feelings, using a Likert scales ranging from strongly agree to strongly disagree.

During the interview, the participant was able to vividly recall where she was during times of each distress, and what she was told by the administrative team, and their reactions to her response. However, she was unable to recall her replies to their instructions. When remembering her responses, they reported not fully recall all that she did say, only that it was vague. No details could be recalled, except that she was upset, and expressed this to administration. When asked about her response to each incident individually, she was able to only recall (a) that she was angry, but not her reactionary response she provided. (b) she was not able to revisit mentally if her responses were perceived in a positive light her intended objective, and (c) that her responses were unsuccessful in helping improve the situation?

The other participant, who comprised of the subject's co-workers, totaled 5 Asian co-workers, and 1 non-Asian. These were three females, with age ranging from mid-twenties, and two administrative staff in the mid-forties. The non-Asian male was in his mid-thirties. The Non-Asian co-worker, was of an American background. These participants were interviewed by face to face, and completed an online assessment designed by Rosenberg Self-Esteem Scale (Rosenberg, 1965).

Due to the volatile environment created by the subject, most of her co-works often excused themselves when she was around or avoided communicating with her. She often presented a fixed and rigid views about how things were supposed to function, and contested strongly any opposing views. She was very critical of other performance and required others to extend a grace period for her faux pas.

\section{Results}

The participants scored 12 out of 30 on the Rosenberg Self-Esteem inventory. Any score below 15 is considered an indication of a low-self-esteem. During the interview with the participant, the participant was able to recall vividly where and when each request was made of her by the administration. She, however, 
had difficult time recalling her direct responses/comments to their requested. She was able to recall that she was upset about them. On the other hand, she could not recall exactly what she thought led her to become upset, only that it was encroachment on her occupational liberties. During the interview, she was not able to recall any actions to which she partook which might have caused her to be at odds with the office staff or administration. Using a Likert scale to score her responses to the demands placed upon her, with 1 being good and 10 being very poor, she scored her responses as a 4, for contributing to the office volatility. Using the same Likert scale, she scored their actions towards her, she rated them at an 8 . What would have caused them to move 1 scale point down would have been her response was, if they had changed the schedule to accommodate her. What would have move them down two score points, she reported, that if they had negotiated with her, her work schedule. When asked what would have moved them down three scales to a 5 , she reported if they were more open-minded. What would have moved them down to a scale of 4, points, she reported that if they had given her students who did not have difficulty grasping the assignments possessing language learning difficulties. She couldn't stand dealing with slow learners.

The participant was asked to rate each of her co-workers on a Likert scale of cooperation, likeability and trustworthiness, where 1 was strongly agree to 10 being strongly disagree, she rated all the females at a 7 , lack of cooperation. The likeability was rated at 9 and trustworthiness at 7 . For the non-Asian worker, she rated him at 4, 3 and 1 respectfully. When asked, if she ever worked with females who were not of Asian heritage, and if so, what was the working relationship like, she reported that she never really got along with other females.

When asked about her response to each incident individually, she was able to only recall that she was (a) angry, but not the reactionary response she gave. Additionally, she was unable to recall if her responses were perceived in any light other than her intended objective, and (c) that her responses were unsuccessful in helping improve the situation? When asked, about the process how she responded, she was not able to discuss them in detail, only that she was protecting her honor and integrity. She was asked what percentage of her responses was immediate, scheduled or delayed. She recalled all being immediate, and adequately suited for the situation. For her immediate did not mean unplanned, however, the planned process was based upon the presenting data and no new independent data was sort after. When asked about the consequences to the response, she felt the administration was calculating and scheduling. They refused to response immediately to her, but waited and scheduled theirs when she was relaxed or had forgotten the event. When asked, were any of the administration response favorable to her position, she admitted no. When asked, could she have used another method to address her disagreement or discomfort, she retorted, no, it was the best course of action at the time. When asked, did other independent evidence come to light about the incident(s) later on, she admitted, some occasionally did. When asked, what she would have done differently if the situation had been repeated, she responded, she would have responded in the same way. When asked, was the outcome what she had expected, she replied, no and that it was much too severe. When asked about her word choice for response and timing, if it could have been calibrated differently to accommodate a window for the administration, and staff to adjust to her request, she reported that they had already made up their minds and nothing was going to change that. When asked, if there were others in similar situations, she responded, rarely. When asked if they ever found the instructions or conditions unfavorable, she retorted of course. When asked, if they were able to negotiate a better term of conditions, she replied, they were, but they had others to assist them in the process. When asked, if they ever seemed unable to negotiate favorable terms of conditions, she did not recall. When asked if others were able to navigate around certain conditions within the work place, she was unable to recall ever seeing them complain. When asked if others and administration were always on good terms, she stated no. She reported that at times it appeared that they were being abused. When asked how they handled it, she reported that they allowed administration to walk all over them.

When asked, what might have caused her to distrust others in the work environment she reported that, she reported that they engineered a plot. When asked what evidence she possessed, to validate this claim, she reported sensing something was up, and then she noticed their behavior towards her changed and finally 
DOI: $10.21522 /$ TIJPY.2016.02.02.Art001

ISSN: $2518-8852$

their actions. When asked, did she attempt to thwart the growth at any stage, she reported, no, she waited until they confronted her. When asked, was her response passive or active, she reported she was in full defensive mood, and let them have it.

The other participants in the study Rosenberg Self-Esteem inventory were as follows: for the females, $17,19,19,21,23$ respectively. The male score was 16 . Using a Likert scale, when asking them to rate the relationship with the subject from agreeable to difficult to work with, 10 been very difficult to 1 being agreeable, the results are as follows. The five females rated her as $6,8,5,9,5$. The male rated her as 7 . When asked, what could have caused her score to drop, 1 point lower, their responses were as follows: she needed to exercise more personal restraint, complain less, be more sociable, easier to work with, and reduce the tantrums?

\section{Discussion}

The participant's score on Rosenberg Self-Esteem inventory was 12/30 indicating low self- self-esteem or personal appreciation. Horney (1940), indicated that persons, who seek out relationship with a significant other and is unmet, results in a form of neurotic relationship development. This could help to explain her fragile relationships with females. Further, during the interviews the participant expressed difficulty relating to others. She indicated a desire to improve social relations; however, she seemed unable to understand the social cues needed to make a smooth sustainable and long-lasting interaction possible. This is supported by (Ainsworth, 1964), how highlighted due to limited social skills, such persons find developing bonds difficult.

Ainsworth (1964), further supports the idea that persons with such range dimensions often have interpersonal relationship skills deficiencies. Furthermore, because of these social impediments, she was unable to detect any fault within her reasoning process. The participant pointed out that she experienced a point 8 on the Likert Scale as it related to frustration with colleagues and supervisors. This might be due in part to what Acton (2003), termed as a low threshold tolerance for others reactions and interactions with her response. When using the same Likert scale of how she performed, she scored herself and responses as a 7, indicating her ability to work and perform well. According to Glasser (1998), this might help to explain her reports of the need for power through competency. When asked if she was difficult to work with, she said no and that she did her best to work with others. According to Ainsworth (1964), this might be viewed as a need to move towards and against others to attain affection, approval and power all at the same time. The vast disparity between the Likert scale scores she provided, and the rating which the participant received might be explained in what (Beck, 1976) called cognitive distortion. The participant was not able to draw linkages between the differences, nor was the participant able to view any limitation on her part as a result of the disparity. This might be explained by McCrea and Hirt (2001) who reported that such person was protecting her global and personal self-esteem. She was able to recall with significant detail how she was victim of circumstance and poor social relations, and not her contributing part whether consciously or unconsciously. Varize and Funder (2006), purported that impulsive nature, inhibits deeper comprehension of events. On examining the relationship network established and maintained by the participant, it showed a narrow window of social comfortableness and networking skills. Perhaps this can be explained in the works of Ainsworth (1964), who demonstrated insecure and ambivalent attachment styles, seeking to move towards others, and yet rejecting them at the same time.

When asked about her response to each incident individually, she was able to (a) only recall that she was angry, but not the reactionary response she gave, might be explained in the theory by Beck (1976), who pointed out the need to (1) select parts of the whole- selective arbitration, (2) taking a matter and maximizing- creating significance, (3) and personalizing it- making it an private attack. As she saw it as a personal attack on her values, integrity and competency. As it relates to (b), if her reactions were perceived in any light other than her intended objective - to which she admitted they were not, however, she was sure than no matter what she had said, it was justified, and within reason. This could be understood by the Acton (2003) who pointed out natural tendency to engage in automatic and or fixed responses. Baumeister, Dale, 
and Sommer (1998), highlighted that the true cause of social anxiety is being overly directed in the most non-threatening way- those whom she does not fear because they are not relatives. Thus, her immediate reaction with little thought of the implications, because she has never mastered the willpower to regulate her emotions or learn how to channel them effectively (Budhananda, 1990). Thus, the negative consequences hold little sway over her processing. As a consequence, her responses were unsuccessful in helping improve the situation. When asked additionally, about how she derived her reactionary response, she was not able to discuss them in detail only that she was protecting her honor and integrity. This points toward her need to protect her global self-image (Acton, 2003). She was asked what percentage of her responses were immediate, scheduled or delayed. She recalled most being immediate, and adequately suited for the situation, this too can be explained by (Acton, 2003, Budhananda, 1990, and Berlin \& Hollander, 2008), as the lack of willpower to regulate her feelings when perceived threats arose, because they were viewed as a novelty, and thus, with no prior historical examples to guide and gauge her processing of them, when was unable to seek an alternative response. When asked about the consequences to the response, she felt the administration was calculating and scheduling (DSM-5, 2013), thus her generalized anxiety was unconscious and ability to plan a strategic response was limited, as the source of her discomfort was always nebulous. They refused to response immediate to her, but waited and scheduled theirs until she was relaxed or had forgotten the event.

In her impulsiveness, she was unable to process her request in relation to (a) the companies' responsibilities to the customers, (b) in relation to the other employees whose schedule might have been also altered or would be altered to accommodate her request (Varize \& Funder, 2006). She was unable to figure out why she was a victim (Beck, 1976), nor was she able to understand any links between her past experiences (Acton, 2003), because for her each experience was view as a novelty (Berlin and Hollander, 2008), and this kept her from progressing (Beck, 1976, DSM-5, 2013). As a result, she was caught in a vortex of a never ending repeated cycle of discomforting experiences and repeating the same actions as if they were new (Acton, 2003, Budhananda, 1990, Varize \& Funder, 2006). She had no template or example from which to ground her experience or to her help her to reflect upon (Bandura, 1961).

Finally, she was unable to see how other coped with similar situations because of arbitrary selection process (Ainsworth, 1964, Bandura, 1961, Budhananda, 1990, Varize \& Funder, 2006). As she reported, it rarely happened to them and that they had external help to them manage the crisis situation.

\section{Conclusion}

Persons who engage in self-sabotaging behavior can be influenced by impulsivity or rush to judgment because they are directed by need to gain power through competency of others and situations, and thus acquire their privately needed affection by moving towards and against others whom they view as threaten to their personal self-esteem. Understanding the role of impulsivity and, willpower could help shed some new knowledge on the issue of self-esteem and self-sabotaging behavior. There appears to be an association between rushing to judgment and the level of cognitive processing that can be engaged in when the need for approval is paramount in the lives of persons. Perhaps more research is needed in exploring insecurity and affection, which seems to regulate the degree of impulsivity, which might facilitate self-sabotaging behavior.

\section{References}

[1]. Acton, S. G. (2003). Measurement of impulsivity in a hierarchical model of personality traits: Implications for Substance Use. Substance Use \& Misuse: Marcel Dekker, Inc. New York. Vol. 38, No. 1, pp. 67-83, 2003

[2]. Ainsworth, M. D. (1964). Patterns of attachment behavior shown by the infant in interaction with his mother. Merrill-Palmer Quarterly of Behavior and Development, 51-58.

[3]. American Psychiatric Association. (1994). Diagnostic and statistical manual of mental disorders (4th ed., text rev.). Washington, DC: Author

[4]. American Psychiatric Association. (2013). Diagnostic and statistical manual of mental disorders (5th ed.). Washington, DC: Author. 
DOI: $10.21522 /$ TIJPY.2016.02.02.Art001

ISSN: $2518-8852$

[5]. Baumeister, R., Bratslavsky, E., Muraven, M., \& Tice, M.D. (1998). Ego depletion: Is the Active Self a Limited Resource? Journal of Personality and Social Psychology, 1998, Vol. 74, No. 5.

[6]. Baumeister, R. E, Heatherton, T. E, \& Tice, D. M. (1994). Losing control: How and why people fail at selfregulation. San Diego, CA: Academic Press

[7]. Baumeister, D, \& Sommer, k. L. (1998). Freudian defense mechanisms and empirical findings in modern social psychology: Reaction formation, projection, displacement, undoing, isolation, sublimation, and denial. Journal of Personality. Vol. 66. P. 1081-1124.

[8]. Baumeister, R., Tice, M.D., \& Hutton, D.G. (1990). Self-presentational motivations and personality differences in self-esteem. Journal of Personality.

[9]. Baumeister, R., \& Vohs, K. (2007). Self-regulation, ego depletion, and motivation. Social and Personality Psychology Compass, 1(1), 1-14.

[10]. Beck, A.T. (1976). Cognitive therapy and emotional disorders. New York: International Universities Press.

[11]. Berlin, A. H. \& Hollander, E. (2008). Understanding the Differences between Impulsivity and Compulsivity. Psychiatric times. http://www.psychiatrictimes.com/impulse-control-disorders/understanding-differences-betweenimpulsivity-and-compulsivity.

[12]. Berlin, G. S., \& Hollander, E. (2014). Compulsivity, impulsivity, and the DSM-5 process. CNS Spectrums, 19(1), 62-68. DOI:10.1017/S1092852913000722

[13]. Budhananda, S. (1990). Will power and its development. Prabuddha Bhar.ata: Calcutta. http://estudantedavedanta.net/WillPo.pdf

[14]. Budner, S. (1962). Intolerance of ambiguity as a personality variable. Journal of Personality, 30, 29-50. Cherry, K. (2016). Willpower 101: The psychology of self-control https://www.verywell.com/willpower-101-the-psychologyof-self-control-2795041

[15]. Eronen, S., Nurmi, J., \& Salmela-Aro, K. (1998). Optimistic, defensive-pessimistic, impulsive and selfhandicapping strategies in university environment. Learning and Instruction: Pergamon. Britain. Vol. 8. No. 2, pp. 159-177, 1998.

[16]. Glasser (1998), Choice theory. A new psychology of personal freedom. Harper Collins Publisher.

[17]. MacKillop, J., Weafer, J., Gray, C. J., Oshri, A. Palmer, A., \&. Wit, H. (2016). The latent structure of impulsivity: impulsive choice, impulsive action, and impulsive personality traits. Springer-Verlag: Berlin Heidelberg.

[18]. McCrea, S. M. \& Hirt, E.R (2001). The role of ability judgments in self-handicapping. Personality and social psychology bulletin. Indiana University-Bloomington. 27 (2001), 10, pp. 1378-1389.

[19]. Personality and Social Psychology Review. Lawrence Erlbaum Associates, Inc. 2006. Vol. 10, No. 2, 154-165.

[20]. Rosenberg, M. (1965). Society and the adolescent self-image. Princeton, NJ: Princeton University Press. Varize, S. \& Funder, D. C. (2006). Impulsivity and self-defeating behavior of narcissists. 